\section{HINOS DE FUTEBOL EM PORTUGAL: DOS HINOS MARCIAIS AOS POPULARES}

Elcio Loureiro Cornelsen*

RESUMO: Nossa contribuição visa à análise comparativa das letras de hinos de clubes de futebol de Portugal à luz da fase de transição dos hinos marciais das primeiras décadas do século XX para os hinos populares a partir da década de 1950. Para isso, elegemos as letras dos hinos do Sport Lisboa e Benfica e, respectivamente, do Futebol Clube do Porto, de Portugal, para comporem o corpus de análise. Em termos metodológicos, a partir de um olhar transdisciplinar, pensamos a relação entre literatura, música e futebo através da análise das letras de hinos, tomando por base seus elementos líricos, épicos e dramáticos.

PALAVRAS-CHAVE: futebol e poesia; futebol e música hinos de clubes; futebol e discurso. *cornelsen@letras.ufmg.br

Doutor em Estudos Germânicos pela Freie Universität Berlin/Alemanha, Professor Associado II e credenciado junto ao Programa de Pós-Graduação em Estudos Interdisciplinar de Pós-Graduaçáo em Estudos do Lazer, da EEFFT/UFMG. Bolsista de Produtividade em Pesquisa - nivel 2 do CNPq e do Programa Pesquisador Mineiro da FAPEMIG. Co-fundador e Futebol, Linguagem e Artes da FALE/UFMG.

ABSTRACT: Our contribution aims at a comparative analysis of the lyrics of anthems of football clubs in Portugal in light of the transition from martial anthems of the first decades of the twentieth century to the popular anthems from the 1950s. For this, we chose the lyrics of the anthems of Sport Lisboa e Benfica and, respectively, of Futebol Clube do Porto of Portugal to compose the corpus analysis. In terms of methodology, from transdisciplinary look, we think the relationship between literature, music and football by analyzing the lyrics of the anthems, based on its lyric, epic and dramatic elements.

KEYWORDS: football and poetry; football and music club anthems; football and speech. Literários da FALE/UFMG, credenciado do Program
O presente artigo resulta de pesquisa apresentada em forma de pôster durante o XIV. Congresso Internacional Ciências do Desporto e Educação Física dos Países de Língua Portuguesa, realizado de 02 a 04 de abril de 2012, no Minas Centro, em Belo Horizonte, e, respectivamente, em 05 de abril de 2012 na UFOP, em Ouro Preto. 
1. ROSENFELD. O teatro épico, p. 3-26.

2. CORNELSEN. Hinos de futebolaspectos épicos e dramáticos, $\mathrm{s} / \mathrm{p}$.

\section{INTRODUÇÃO}

Este breve estudo tem por meta a análise comparativa das letras de hinos de clubes de futebol de Portugal, levando-se em conta a fase de transição dos hinos marciais das primeiras décadas do século XX para os hinos populares, ocorrida a partir da década de 1950.

A partir de um olhar transdisciplinar, pensamos a relação entre literatura, música e futebol através da análise das letras de hinos, tomando por base seus elementos líricos (forma estrofação; metrificação; rima), épicos (cena enunciativa espacialização; feitos heróicos e conquistas e/ou virtudes identidade simbólica) e dramáticos (afetividade; apelo à fidelidade; emoção; louvor).

Para isso, elegemos as letras dos hinos do Sport Lisboa e Benfica (1929 e 1953) e, respectivamente, do Futebol Clube do Porto (1922 e década de 1950), de Portugal para comporem o corpus de análise.

Em termos teóricos, fundamentamos nossa análise a partir das reflexões propostas por Anatol Rosenfeld ao discutir os gêneros literários de acordo com sua adjetivação, ou seja, como elementos épicos, líricos e dramáticos que podem estar presentes, simultaneamente, numa dada obra ou texto. ${ }^{1}$

Por sua vez, baseados nos resultados de outro estudo realizado em 2009, ${ }^{2}$ desenvolvemos um modelo de análise formado por categorias correspondentes para cada um dos respectivos elementos:

\section{a. elementos líricos}

Primeiramente, todo texto poético pode ser analisado em seus aspectos formais, desde a forma rígida do poema (não tão comum em letras de hinos de clubes de futebol), a estrofação, a metrificação, e o tipo de rima empregado.

\section{b. elementos épicos}

Trata-se do grupo de elementos que estruturam a narrativa (o modo de se enunciar) e possibilitam a construção de uma imagem heroica do clube, seja a partir de aspectos simbólicos (menção às cores, ao distintivo, às designações etc.), seja a partir de referências espaciais (caráter local, nacional, internacional), ou mesmo por menções a feitos heroicos e conquistas ou virtudes que se atribui ao clube.

\section{c. elementos dramáticos}

Por fim, o terceiro grupo é mais comumente encontrado em letras de hinos populares, pois diz respeito ao emprego de terminologia que marca a afetividade, o apelo à fidelidade, a emoção e o louvor em relação ao clube.

A seguir, detalharemos esses aspectos, baseando-nos na relação entre literatura, música e futebol. 
3. BILAC; PASSOS. Tratado de versificação, p. 110

\section{LITERATURA, MÚSICA E FUTEBOL: OS HINOS DESPORTIVOS}

Desde o início, a composição de hinos para as agremiações de futebol ampliaram, significativamente, o encontro entre música e futebol, integrando a literatura, mais especificamente a arte poética. Pois o hino é uma criação mista, produzida por um discurso lítero-musical e, como tal, marcada pela inclusão simultânea do elemento musical e do verbal.

Por definição, hino (do grego: ü $\mu \nu 0 c$ hymnos, "estrutura sonora”) é uma composição poético-musical de louvor ou exaltação. O hino é expressão de entusiasmo elevado, originalmente, um poema ou cântico de veneração ou louvor à divindade, portanto, de cunho religioso, escrito especificamente para louvor ou adoração tipicamente endereçado a deuses e heróis. ${ }^{3}$

$\mathrm{Na}$ Antiguidade, o hino era uma canção de enaltecimento, cantada em cerimônias ao som de cítara ou de outros instrumentos musicais, e se destinava à veneração de deuses, de heróis ou da própria natureza. Era encontrado em várias culturas, como a egípcia, a romana e a grega, nos hinos de devoção a Dionysos. Na Bíblia também se encontram hinos, como, por exemplo, no Livro dos Salmos. Uma modalidade de hino presente na Antiguidade era o "epinício", dedicado ao vencedor de disputas atléticas, como, por exemplo, os Jogos Olímpicos: "um coro, composto por seus amigos e coetâneos, após a realização dos imprescindíveis sacrifícios aos deuses, cantava, acompanhado pelo som da flauta e da lira, o epinício (a canção da vitória), escrito e musicado por um poeta famoso". ${ }^{4}$ E não se tratava de uma mera canção de ocasião. Em geral, ela era divulgada pelo mundo helênico, como ocorrera, por exemplo, com a ode dedicada pelo poeta Píndaro a Píteas, jovem atleta de Egina que conquistara a vitória no pancrácio - misto de luta e pugilismo -, nos jogos de Neméia, em 485 a.E.C. ${ }^{5}$

Por sua vez, na Idade Média o hino tornou-se uma forma de canção religiosa coesa e composta de várias estrofes. Tal forma é empregada até hoje no Canto Gregoriano e em canções da liturgia cristã.

Já na Idade Moderna, o hino deixou de ser uma forma de composição musical exclusiva do âmbito religioso. Surge, então, o hino nacional (de devoção à nação ou à pátria), o hino partidário (de devoção a um partido político), o hino de organizações em geral e o hino desportivo (de devoção a um clube ou agremiação). De acordo com Olavo Bilac e Guimaraens Passos, num sentido contemporâneo, "[r]igorosamente, dá-se hoje o nome de hymno a uma composição poética, acompanhada ou não de música, em que se exalta alguém, ou se celebra algum acontecimento, e com que se excitam os ânimos por uma entoação forte e elevada", ${ }^{6}$ e o hino seria uma forma da poesia lírica que, muitas vezes, se
4. KAKRIDIS; ANDRÓNIKUS. Atletismo na poesia e na arte, $p$ 159

5. Idem, ibidem. versificação, p. 111. 
7. Idem, p. 110.

8. ROSENFELD. O teatro épico, p. 7-8. confundiria com outras duas formas, mais precisamente os cânticos e os salmos. ${ }^{7}$

Todavia, é nas letras dos hinos dos clubes que a literatura se aliará em essência ao futebol e à música, como ocorrera na aliança entre esporte e arte, na Antiguidade. Pois as letras de hinos, muitas vezes, apresentam um grau de sofisticação em termos de elaboração, não obstante o fato do caráter popular que marca o futebol enquanto fenômeno cultural de massa. Para efeito de análise, adotamos o sentido "adjetivo” dos gêneros de acordo com traços estilísticos líricos, épicos e dramáticos. ${ }^{8}$ Em termos de forma em letras de hinos de futebol, embora raros, podemos encontrar sonetos e rondós, e a estrofação pode apresentar também variações, como quartetos, tercetos e dísticos, e sempre um refrão. A versificação varia entre isométrica (todos os versos de uma estrofe seguem uma regularidade métrica), parcialmente isométrica (alguns versos de uma estrofe seguem uma regularidade métrica), e heterométrica (os versos de uma mesma estrofe não seguem uma regularidade métrica). Os versos podem se constituir metricamente de modo uniforme como redondilhas menores, redondilhas maiores, eneassílabos, decassílabos etc., ou mesmo serem marcados por uma variação métrica irregular com versos polimétricos, fato que pode ocorrer também com a disposição e o grau de regularidade de rimas (rimas cruzadas, rimas emparelhadas, rimas interpoladas, rima completa, rima incompleta, rima perfeita, versos brancos etc.)

Por sua vez, o estudo literário das letras de hinos de futebol nos possibilita a avaliação de seus componentes épicos. Num estudo prévio que elaboramos em 2009, por ocasião de uma entrevista dentro do programa esportivo Meio de Campo, da Rede Minas, ${ }^{9}$ constatamos que o aspecto épico dos hinos de futebol se constitui, basicamente, a partir de quatro componentes: (1) a cena narrativa; (2) a espacialização; (3) feitos heróicos e conquistas e/ou virtudes; (4) identidade simbólica. A cena narrativa diz respeito ao modo como instância lírica se apresenta, ora como um "eu" que evidencia um caráter individual, ora como um "nós" que apela ao coletivo da torcida no sentido de pertencimento, ou mesmo como um "tu", dirigido ao clube como objeto de devoção e louvor, o que gera um efeito de proximidade e intimidade. Já a espacialização, marcada textualmente, e pensada aqui na junção entre espaço e ação no devir, dimensiona o caráter identitário de um determinado clube em relação ao espaço e pode variar desde o âmbito local, passando pelo nacional e, mais raramente, chegando ao internacional, uma vez que, como apontado anteriormente, os hinos de clubes foram compostos, sobretudo, num período em que o futebol ainda não conhecia o grau de globalização dos nossos dias. Feitos heróicos e conquistas e/ou virtudes também se constituem
9. CORNELSEN. Hinos de futebol - aspectos épicos e dramáticos, $\mathrm{s} / \mathrm{p}$. Trata-se do estudo intitulado "Hinos de futebol - aspectos épicos e dramáticos", elaborado a partir da análise das letras de hinos de 13 clubes brasileiros: América, Botafogo, Flamengo, Fluminense, Vasco da Gama, Corinthians, Palmeiras, Santos, São Paulo, Atlético Mineiro, Cruzeiro, Grêmio e Internacional. A partir da análise das letras, pudemos delimitar as categorias que constituem o aspecto épico que constituem o aspecto epico feitos heróicos e conquistas e/ou feitos heroicos e conquistas e/ou
virtudes; identidade simbólica) e virtudes; identidade simbólica) e apelo à fidelidade; emoção: louvor), recorrentes na maioria dos casos. 
10. COSTA. Do futebol a uma nova imagem do homem e da sociedade, p. 13-26. como traços característicos das letras dos hinos de clubes de futebol, evidenciando o seu caráter épico, e são pautados, principalmente, pelo emprego de superlativos, como "o maior", "o melhor", "o mais ..." etc. Por fim, a identidade simbólica se constrói nas letras de hinos de futebol através de diversas marcações textuais, seja as cores de determinada agremiação, seja o seu distintivo, bandeira ou mascote, que juntamente com o hino formam o conjunto principal dos símbolos de um clube.

Em termos transdisciplinares, no intuito de delimitar com maior propriedade essas categorias que compõem o elemento épico, devemos atentar para "o funcionamento simbólico e ritualístico do futebol”, "a natureza mítica do futebol”, a "dramatização mítica", a "linguagem simbólica", "o futebol como liturgia do universo", e, enfim, "o futebol como epopéia do humano", aspectos esses destacados por António da Silva Costa em seu estudo intitulado "Do futebol a uma nova imagem do homem e da sociedade", ${ }^{10}$ fundamentado por noções oriundas da Sociologia e da Antropologia.

Além do enfoque do caráter épico, eminentemente narrativo, o estudo literário das letras de hinos de futebol nos permite também avaliar seus componentes dramáticos, que visam à mobilização do torcedor, tornando-se atuante no ato próprio do jogo, como bem ressalta Anatol Rosenfeld:
O verbo "torcer" significa "virar, dobrar, encaracolar, entortar" etc. O substantivo "torcedor" designa, portanto, a condição daquele que, fazendo figa por um time, torce quase todos os membros, na apaixonada esperança de sua vitória. Com isso reproduz-se muito plasticamente a participação do espectador que "co-atua" motoramente, de forma intensa, como se pudesse contribuir, com sua conduta aflita, para o sucesso de sua equipe, o que ele, enquanto "torcida" - como massa de fanáticos que berram -, realmente faz. ${ }^{11}$

De modo semelhante ao aspecto épico, o aspecto dramático dos hinos de futebol se constitui, basicamente, a partir de quatro componentes: (1) a afetividade; (2) o apelo à fidelidade; (3) a emoção; (4) o louvor. Todos esses componentes se expressam textualmente. A afetividade é marcada por termos como "coração", "amado", "querido", "amor” etc. Já o apelo à fidelidade remete à ligação inconteste entre torcedor e clube, marcada textualmente por expressões como "sempre" ou "até morrer". Por sua vez, a emoção se pauta justamente por palavras que evidenciam textualmente o seu caráter, como é o caso dos termos "emoções", "prazer", "feliz", "vibrar" etc. Finalmente, expressões de louvor emprestam ao hino um caráter dramático de devoção, como se o clube assumisse o lugar de objeto de veneração e culto, como, por exemplo, "salve", "glória", "exaltar" etc.
11. ROSENFELD. O futebol no Brasil, p. 94. 
12. COSTA. Do futebol a uma nova imagem do homem e da sociedade, p. 14.
Portanto, de modo visceral, a colaboração da literatura para o âmbito do futebol passa também pelo caráter ritualístico que este adquire ao longo de sua história. Pois os poemas musicados em forma de hinos de louvor e exaltação são partes constituintes dos rituais, cujas raízes, como aponta António da Silva Costa, estão atreladas "ao universo dos mitos e à religião", ${ }^{12}$ e que podem ser encontrados desde a Antiguidade.

A seguir, efetuaremos a analise das letras de hinos de clubes de futebol de Portugal, aplicando, para isso, os conceitos e ferramentas de análise expostos anteriormente.

\section{HINOS DE CLUBES DE FUTEBOL DE PORTUGAL}

3.1. O SPORT LISBOA E BENFICA E SEUS HINOS

Fundado em 1904, o Sport Lisboa e Benfica, um dos clubes mais tradicionais do futebol português, possui dois hinos. O primeiro hino oficial, com letra de Félix Bermudes e música de Alves Coelho, data de 1929:

Todos por um! Eis a divisa,

Do velho Clube Campeão,

Que um nobre esforço imortaliza,

Em gloriosa tradição.

Olhando altivo o seu passado,
Pode ter fé no seu futuro.

Pois conservou imaculado

Um ideal sincero e puro.

\section{REFRÃO}

Avante, avante p'lo Benfica,

Que uma aura triunfante Glorifica!

E vós, ó rapazes, com fogo sagrado,

Honrai agora os ases

Que nos honraram o passado!

Olhemos fitos essa Águia altiva,

Essa Águia heráldica e suprema,

Padrão da raça ardente e viva,

Erguendo ao alto o nosso emblema!

Com sacrifício e devoção

Com decisão serena e calma,

Dêmos-lhe o nosso coração

Dêmos-lhe a fé, a alma!13

O compositor dessa letra, Félix Bermudês, foi presidente do Sport Lisboa e Benfica nos períodos de 1916 a 1917, 1930 a 1931 e, respectivamente, 1945. Ao analisá-la, constatamos que, quanto aos elementos líricos, a letra se compõe de cinco estrofes, sendo quatro quadras e uma quintilha, justamente o refrão, com predomínio de versos octossílabos isométricos ou parcialmente isométricos. Além disso, predominam as
13. Disponível em: http:// universobenfiquista.blogspot. com/2010/03/o-hino-do-benficacensurado-pelo-regime.html. Acesso em 20 de novembro de 2011 
rimas cruzadas nas quatro quadras. Embora a forma da letra não seja marcada (se não fosse pela quintilha, ela teria uma forma de rondó), constata-se certa rigidez na composição formal da letra, traço característico dos primeiros hinos de clubes de futebol, em geral, de caráter marcial.

Por sua vez, ao analisarmos a letra, considerando seus elementos épicos, constatamos que a construção da cena narrativa varia da $3^{a}$ pessoa do singular - "Do velho Clube Campeão, / Que um nobre esforço imortaliza,"; "Pois conservou imaculado / Um ideal sincero e puro." - para a $1^{a}$ pessoa do plural - "Olhemos fitos essa Águia altiva,"; "Dêmoslhe o nosso coração! / Dêmos-lhe a fé, a alma!"; como índice pronominal: "Que nos honraram o passado!"; "Erguendo ao alto o nosso emblema!", e também na $2^{\text {a }}$ pessoal do plural "E vós, ó rapazes, com fogo sagrado, / Honrai agora os ases" - e, finalmente, na $3^{a}$ pessoa do plural - "Honrai agora os ases / Que nos honraram o passado!". Enquanto a 1a pessoa do singular destaca o clube, $1^{\text {a }}$ pessoa do plural enfatiza o pertencimento e o sentido de comunidade dos Benfiquistas. Já a $2^{\text {a }}$ pessoa do plural possibilita a conclamação da torcida enquanto interlocutor, e a $3^{3}$ pessoa do plural releva o papel dos craques do passado.

$\mathrm{Na}$ construção da cena narrativa, constata-se a ausência do emprego de $1^{\text {a }}$ pessoa do singular. Com isso, não há o investimento num eu-lírico, que transmita sua subjetividade diante do clube. Esse é um aspecto comum nos primeiros hinos de caráter marcial, pois a ênfase recai sobre a combatividade e não à afetividade.

Além disso, com relação aos demais elementos épicos, constata-se a ausência de espacialização, sem referência ao âmbito em que o clube atua, mas as virtudes do clube são enaltecidas: nobreza, imortalidade, tradição, altivez, triunfo, honradez, supremacia. Não há marcação explícita de conquistas, e apenas o verso "Do velho Clube Campeão". Em geral, os primeiros hinos exploram justamente as virtudes, sempre atemporais, e não eventos específicos. Mas a identidade simbólica se faz presente na letra do hino composto por Félix Bermudês através dos versos "Olhemos fitos essa Águia altiva, / Essa Águia heráldica e suprema", numa menção ao escudo do Benfica.

Além disso, os elementos dramáticos, cuja função é apelar para a mobilização do torcedor, são marcados textualmente quanto à afetividade - "Dêmos-lhe o nosso coração! / Dêmoslhe a fé, a alma!" - e à emoção "Com sacrifício e devoção / Com decisão serena e calma”. Embora se trate da projeção de um sujeito coletivo, há a construção de uma relação de afeto e devoção ao clube do coração. Porém, a letra não contém elementos dramáticos de apelo à fidelidade ou mesmo de louvor.

Todavia, o primeiro hino oficial do Sport Lisboa e Benfica foi proibido em 1942, durante a ditadura de Salazar, segundo 
14. Disponível em: http:// universobenfiquista.blogspot. com/2010/03/o-hino-do-benficacensurado-pelo-regime.html. Acesso em 20 de novembro de 2011; afirmação semelhante é apresentada também em: http:// ontemvi-tenoestadiodaluz.

blogspot.com.br/2012/12/avanteavante-plo-benfica.html. Acesso em: 01 de maio de 2014, assim como em: http://raivaescondida. wordpress.com/2010/03/15/o1\%C2\%BA-hino-do-sport-lisboae-benfica-banido-pelo-estadonovo/. Acesso em: 01 de maio de 2014.

15. Disponível em: http:// universobenfiquista.blogspot. com/2010/03/o-hino-do-benficacensurado-pelo-regime.html. Acesso em 20 de novembro de 2011. consta, pela conotação comunista da palavra "avante" no primeiro verso do refrão do hino. ${ }^{14}$ Levou algum tempo, até que, em 1953, foi criado o segundo hino oficial com o tema "Ser Benfiquista”, com letra e música de Paulino Gomes Junior:

Sou do Benfica

E isso me envaidece

Tenho a genica

Que a qualquer engrandece

Sou de um clube lutador

Que na luta com fervor

Nunca encontrou rival

Neste nosso Portugal.

(Refrão)

Ser Benfiquista

É ter na alma a chama imensa

Que nos conquista

E leva à palma a luz intensa

Do sol que lá no céu

Risonho vem beijar

Com orgulho muito seu

As camisolas berrantes

Que nos campos a vibrar

São papoilas saltitantes. ${ }^{15}$
Em termos formais, quanto aos aspectos líricos, constata-se que essa letra não possui forma marcada, sendo composta por duas estrofes, uma oitava com versos parcialmente isométricos e uma décima (refrão), também com versos parcialmente isométricos, que variam entre o tetrassílabo, o hexassílabo e a redondilha maior. além disso, predominam as rimas cruzadas (versos 1-4 da $1^{\text {a }}$ estrofe e 1-4 e 8-10 da $2^{\mathrm{a}}$ estrofe) e de paralelas (versos 5-8 da $1^{\text {a }}$ estrofe). Portanto, se comparado com o primeiro hino oficial, o segundo hino ainda apresenta alguns traços formais, porém em menor grau do que o hino anterior.

Antes de prosseguirmos com a análise do segundo hino oficial do Benfica, devemos ressaltar que sua criação deveu-se à proibição do primeiro hino pelo regime ditatorial e, portanto, não tem a ver diretamente com um gesto de popularização dos antigos hinos marciais, como geralmente se constata. Entretanto, constata-se que há uma mudança significativa em termos de menor apego a questões formais, o que é comum também em letras de hinos de caráter popular.

Retomando a análise da letra do segundo hino oficial do Benfica, especificamente em seus elementos épicos, constatamos uma variação da $1^{\text {a }}$ pessoa do singular - "Sou do Benfica / E isso me envaidece"; "Tenho a genica"; "Sou de um clube lutador" -, passando para a $3^{a}$ pessoa do singular "Nunca encontrou rival" (o clube) -, e apresentando também 
versos na $3^{\text {a }}$ pessoa do plural - "As camisolas berrantes / Que nos campos a vibrar / São papoilas saltitantes." - e na $1^{\text {a }}$ pessoa do plural enquanto índice pronominal - "Neste nosso Portugal”; "Que nos conquista”. Se a letra do primeiro hino oficial apresentava a $1^{\text {a }}$ pessoa do plural como predominante, a letra do segundo hino oficial enfatiza a $1^{\text {a }}$ pessoa do singular, numa mudança significativa, pois o enfoque é o torcedor enquanto indivíduo e sua relação com o clube.

Quanto aos demais elementos épicos, a referida letra apresenta índices de espacialização, seja do âmbito nacional (Portugal), seja do âmbito local (campos), aspecto esse ausente na letra do hino anterior. Além disso, não são marcados feitos heroicos na letra do hino, e sim apenas as virtudes: luta, fervor, orgulho, vibração. Já a identidade simbólica ganha peso maior com referência a designações, ao uniforme e à alcunha atribuída ao clube: "Eu sou do Benfica"; "Ser Benfiquista” (nome; designação); "As camisolas berrantes / [...] São papoilas saltitantes” (uniforme; alcunha).

Por sua vez, constata-se também uma mudança com relação aos aspectos dramáticos em relação ao primeiro hino oficial. A afetividade é marcada pelo verso "Risonho vem beijar", havendo também apelo à fidelidade do torcedor nos versos "Sou do Benfica"; "Ser Benfiquista”. Embora o louvor enquanto marca textual, esteja ausente na letra, o fato de a ênfase da cena narrativa recair sobre a $1^{\mathrm{a}}$ pessoa do singular faz com que a emoção também seja marcada nos versos "E isso me envaidece"; "Que na luta com fervor"; "É ter na alma a chama imensa”.

Há, portanto, mudanças significativas no segundo hino, que tende mais para o caráter popular: a ênfase na $1^{\text {a }}$ pessoa do singular, a marcação da espacialização, e um maior número de aspectos que marcam a identidade simbólica, além de marcações textuais emotivas.

\subsection{O FUTEBOL CLUBE DO PORTO E SEUS HINOS}

Fundado em 1893, o Futebol Clube do Porto, outro clube dos mais tradicionais no futebol português, também possui um hino e uma marcha. O hino oficial, com letra do escrito e dramaturgo Heitor Campos Monteiro e música de António Figueiredo e Melo, foi composto em 1922:

Oh meu Porto onde a eterna mocidade

Diz à gente o que é ser nobre e leal

Teu pendão leva o escudo da cidade

Que na história deu o nome a Portugal

Oh campeão, o teu passado

É um livro de honra de vitórias sem igual

O teu brasão abençoado

Tem no teu Porto mais um arco triunfal 
16. Disponível em: http://www. primeiraliga.com/pl/archive/ index.php?t-5638.html. Acesso em 20 de novembro de 2011.
Porto, Porto, Porto, Porto

Porto, Porto, Porto, Porto

Porto, Porto

Quando alguém se atrever a sufocar

O grito audaz da tua ardente voz

Oh, Oh, Porto, então verás vibrar

A multidão num grito só de todos nós

Oh campeão, o teu passado

É um livro de honra de vitórias sem igual

O teu brasão abençoado

Tem no teu Porto mais um arco triunfal

Porto, Porto, Porto, Porto

Porto, Porto, Porto, Porto

Porto, Porto ${ }^{16}$

Em termos formais, a letra do hino oficial do Futebol Clube do Porto não apresenta forma marcada e contem três estrofes, sendo dois quartetos e uma septilha. Os quartetos possuem versos parcialmente isométricos, enquanto a septilha se compõe de versos isométricos. Em termos de metrificação, predomina o hendecassílabo, e as rimas são cruzadas. Constata-se, portanto, certa rigidez em questões formais.

Por sua vez, a cena narrativa constitui-se a partir de diversas vozes, a começar pela $1^{\text {a }}$ pessoa do singular enquanto índice pronominal - "Oh, meu Porto, onde a eterna mocidade" -, passando para a $2^{\text {a }}$ pessoa do singular também enquanto índice pronominal - "Teu pendão leva o escudo da cidade"; "O teu brasão abençoado / Tem no teu Porto mais um arco triunfal"; "O grito audaz da tua ardente voz" -, e culminando com a $3^{\text {a }}$ pessoa do singular - "Teu pendão leva o escudo da cidade" - e com a $1^{\text {a }}$ pessoa do plural enquanto índice pronominal - "A multidão num grito só de todos nós". Se a 1a pessoa do singular instaura o torcedor como indivíduo, e a $2^{\text {a }}$ pessoa do singular instaura um índice dialógico entre torcedor e clube, a $3^{\text {a }}$ pessoa do singular possibilita a narração sobre o clube, e a $1^{\text {a }}$ pessoa do plural enfatiza o caráter de pertencimento à comunidade de torcedores do Porto.

Com relação aos demais elementos épicos, constata-se que a letra contém índices de espacialização nos versos "Teu pendão leva o escudo da cidade / Que na história deu o nome a Portugal", estabelecendo uma relação entre o âmbito local (cidade) e nacional (Portugal). Embora os feitos heroicos e as conquistas não sejam textualmente marcados, a letra apresenta um leque de virtudes: juventude, nobreza, lealdade, honradez, triunfo, audácia, vibração. E a identidade simbólica é amplamente explorada em termos textuais: desde o escudo - "Teu pendão leva o escudo da cidade / Que na história deu o nome a Portugal." e "O teu brasão abençoado / Tem no teu Porto mais um arco triunfal” -, até a designação 
- "Oh, meu Porto, onde a eterna mocidade"; "Porto, Porto, Porto, Porto / Porto, Porto, Porto, Porto / Porto, Porto"; "Oh, Oh, Porto, então verás vibrar".

Com relação aos aspectos dramáticos, constata-se a ausência de termos que marcam o apelo à fidelidade. Todavia, os demais elementos dramáticos são evidentes no texto como a afetividade - "Oh, meu Porto, onde a eterna mocidade" -, a emoção - "Quando alguém se atrever a sufocar / O grito audaz da tua ardente voz / Oh, Oh, Porto, então verás vibrar / A multidão num grito só de todos nós" - e o louvor - "Oh, meu Porto, onde a eterna mocidade", "Oh, campeão, o teu passado"; "Porto, Porto, Porto, Porto / Porto, Porto, Porto, Porto / Porto, Porto"; "Oh, Oh, Porto, então verás vibrar".

Portanto, o hino oficial do Futebol Clube do Porto contém alguns aspectos que não são típicos dos hinos marciais, como, por exemplo, a enunciação da $1^{\text {a }}$ pessoa do singular enquanto índice pronominal, ou mesmo a afetividade e a emoção em termos dramáticos. Além disso, a letra revelou sua riqueza quanto a seus elementos épicos.

Ainda hoje, o hino oficial do Futebol Clube do Porto como não poderia deixar de ser, é tocado em eventos especiais do clube, ou mesmo quando a equipe entra em campo nas partidas disputadas em sua casa, no Estádio do Dragão.
Todavia, essa não é a única canção dedicada ao clube. Há também a marcha do Futebol Clube do Porto, que também desfruta do status de segundo hino:

Cantemos com voz sonora a toda a hora Pois somos Portistas e sempre bairristas Pelo nosso Porto

Gritamos com todo o ardor o nosso amor Levamos o estandarte e em qualquer parte Do nosso Porto

Porto, Porto, Porto

És a nossa glória

Dá-nos neste dia

Mais uma alegria

Mais uma vitória

Porto, Porto, Porto

És a nossa glória

Dá-nos neste dia

Mais uma alegria

Mais uma vitória

É tão nobre a tua história a tua memória Gritemos sem cessar p'ra te ajudar

Ai ao nosso Porto

O teu passado brilhante nunca distante 
Em nós está presente e eternamente Ao nosso Porto

Porto, Porto, Porto

És a nossa glória

Dá-nos neste dia

Mais uma alegria

Mais uma vitória

Porto, Porto, Porto

És a nossa glória

Dá-nos neste dia

Mais uma alegria

Mais uma vitória ${ }^{17}$

Em nossa pesquisa, infelizmente, não nos foi possível identificar a autoria da Marcha do Futebol Clube do Porto. Deduz-se, entretanto, que se trata de música dos anos 1950 que, assim como o hino, em sua versão gravada conta com a interpretação magistral da cantora Maria Amélia Canossa. Aparentemente, a necessidade de criação da marcha foi gerada por mera mudança de ordem estética.

Com relação a aspectos formais, a letra da marcha não apresenta forma marcada e contém três estrofes, sendo duas sextilhas com versos parcialmente isométricos e 01 décima (refrão) composta por versos isométricos. Há o predomínio de versos hendecassílabos, e as rimas não seguem um formato de tipos de versos, havendo paridade de estrutura de rimas entre a $2^{\text {a }}$ e a $3^{\text {a }}$ estrofes. Há, portanto, certa formalidade quanto aos aspectos poéticos que compõem a letra da marcha.

Por sua vez, com relação aos aspectos épicos, a letra da marcha do Futebol Clube do Porto apresenta diversidade de enunciação, passando da $2^{\text {a }}$ pessoa do singular - "Porto, Porto, Porto / És a nossa glória / Dá-nos neste dia / Mais uma alegria”, e também como índice pronominal: "É tão nobre a tua história a tua memória"; "O teu passado brilhante nunca distante" - para a $3^{\text {a }}$ pessoa do singular - "É tão nobre a tua história a tua memória"; "O teu passado brilhante nunca distante" -, e culminando com a 1 a pessoa do plural - "Cantemos com voz sonora a toda a hora / Pois somos Portistas e sempre bairristas / Pelo nosso Porto / Gritamos com todo o ardor o nosso amor / Levamos o estandarte e em qualquer parte / Do nosso Porto". Enquanto a $2^{\text {a }}$ pessoa do singular estabelece um índice dialógico entre torcida e clube, a $3^{\mathrm{a}}$ pessoa do singular possibilita o relato sobre o clube, e a $1^{\text {a }}$ pessoa do plural enfatiza o sentimento de pertencimento à coletividade de torcedores do Porto. Portanto, há aspectos na letra da marcha que são típicos dos hinos marciais quando se trata da cena narrativa, pois não há, por exemplo, o investimento na $1^{\text {a }}$ pessoa do singular, típica das letras de hinos populares.

Com relação aos demais elementos épicos, constata-se a presença de um índice de espacialização local (Porto), além do
17. Disponível em: http://www. primeiraliga.com/pl/archive/ index.php?t-5638.html. Acesso em 20 de novembro de 2011. 
elenco de virtudes: glória, nobreza, tradição, bem como de versos que marcam a identidade simbólica através da designação: "Pois somos Portistas e sempre bairristas / Pelo nosso Porto".

Já em termos dramáticos, apenas o louvor não é marcado textualmente. Constata-se a marca de afetividade no verso "Gritamos com todo o ardor o nosso amor", e o apelo à afetividade se faz presente no verso "Levamos o estandarte e em qualquer parte". A emoção também encontra expressão nos versos "Cantemos com voz sonora a toda a hora"; "Mais uma alegria"; "Gritemos sem cessar p'ra te ajudar".

A partir de nossa análise, podemos deduzir que a letra da marcha do Futebol Clube do Porto apresenta tanto elementos marciais (emprego de $1^{\text {a }}$ pessoa do plural) quanto de elementos populares (a marcação de afetividade e de emoção).

\section{DOS HINOS MARCIAIS AOS POPULARES: UM}

\section{ESTUDO COMPARADO}

Iniciaremos nosso estudo comparado, partindo dos aspectos líricos. Dentre as letras analisadas, nenhuma possui forma marcada (rondó, rondel, soneto etc.). Porém, as letras dos primeiros hinos oficiais do Benfica e, respectivamente, do Porto apresentam maior rigidez quanto à estrofação, à versificação e à estrutura das rimas. Isso não significa que nos segundos hinos oficiais os aspectos formais recebam menor atenção. O que ocorre é uma espécie de "abrandamento" dessa rigidez, e um dos aspectos que pode contribuir para isso é de ordem melódica, ao se passar do hino marcial para a marcha popular, aspecto esse, aliás, não contemplado no presente estudo, uma vez que nosso enfoque recai apenas sobre a letra da música.

Com relação aos aspectos épicos, especificamente na constituição da cena narrativa, constata-se um predomínio da $1^{a}$ pessoa do plural nas letras dos hinos analisados. Isso se deve ao fato de a individualidade ser preterida em prol do sentimento de coletividade e de pertencimento ao grupo de torcedores de uma dada agremiação.

Ainda com relação à constituição da cena narrativa, constata-se o emprego da $1^{\text {a }}$ pessoa do singular no segundo hino oficial do Benfica. No caso do hino do Porto, ocorre uma inversão: enquanto a $1^{\text {a }}$ pessoa do singular aparece no primeiro hino, ela está ausente na letra da marcha.

Além disso, constata-se também que a $2^{\text {a }}$ pessoa do singular, em geral, utilizada para construir uma cena dialógica entre torcedor e clube, está presente na letra do hino do Porto, que explora mais o aspecto de idolatria. E a $3^{\mathrm{a}}$ pessoa do singular, empregada para enunciar sobre os feitos e virtudes do clube, também se faz presente nas letras analisadas.

De todos esses traços, diríamos que a passagem da $1^{\text {a }}$ pessoa do plural para a $1^{\text {a }}$ pessoa do singular é a marca mais significativa 
da transição do hino de caráter marcial para o hino popular, pois explicita a subjetividade do torcedor enquanto indivíduo, dando margem a outros aspectos, anteriormente ausentes, como índices de afetividade, emoção e louvor.

Por sua vez, com relação aos índices de espacialização, constata-se a ausência de termos espaciais apenas no primeiro hino do Benfica, e as incidências dos demais hinos derivam dos âmbitos local e nacional, não havendo nenhum caso de termo que aludisse ao âmbito internacional. Sem dúvida, isso tem a ver com o contexto em que tais hinos foram criados. Os hinos do Porto e do Benfica datam das décadas de 1920 e, respectivamente, de 1950, épocas em que o futebol não conhecia um grau de internacionalização e globalização dos dias atuais. Não é por acaso que, em vários cantos das torcidas nas arquibancadas, há alusão a triunfos recentes conquistados em nível mundial, num processo de atualização da imagem de determinado clube.

Com relação aos índices textuais que aludem a feitos heroicos e conquistas ou virtudes, constatamos que eles são recorrentes em ambas as letras analisadas. A diferença, nesse caso, está no fato de que predominam as virtudes, sempre atemporais, enquanto os feitos heroicos e conquistas estão ausentes. Nos hinos de clubes portugueses, não é comum a indicação de conquistas específicas, mesmo naqueles hinos que já não apresentam mais a mesma rigidez formal dos hinos marciais.
Já a identidade simbólica aparece tanto nos primeiros quanto nos segundos hinos do Benfica e do Porto. Em geral, a identidade simbólica é textualmente construída a partir de determinado tipo de expressão, como é o caso das cores do clube, do escudo, ou mesmo das designações e alcunhas.

Por fim, com relação aos aspectos dramáticos, constatamos que os hinos do Benfica e, respectivamente, do Porto apresentam termos que aludem à afetividade, embora não predomine a $1^{\text {a }}$ pessoa do singular, mas sim a $1^{\text {a }}$ pessoa do plural. Identifica-se, também, uma variação com relação ao apelo à fidelidade, que está ausente nos primeiros hinos do Benfica e do Porto, ao contrário da emoção enquanto índice discursivo, marcada textualmente nos hinos analisados. Já o louvor está ausente nos dois hinos do Benfica e no segundo hino do Porto. Portanto, afetividade, apelo à fidelidade e louvor são os aspectos dramáticos que se expressam através da mudança dos hinos marciais para os populares no âmbito do futebol português.

\section{CONSIDERAÇÕES FINAIS}

Constatamos que os hinos, enquanto parte do arsenal de símbolos de toda agremiação, contribuem para a construção da imagem do clube, mas também estão sujeitos a atualizações.

Tais atualizações podem ser de ordem política (Benfica) ou estética (Porto). Embora nosso estudo não tenha enfocado 
18. ANDERSON. Imagined Communities, p. 7. o canto das torcidas entoado nos estádios, constata-se que, cada vez mais, tais cantos também são formas de atualização (p. ex., de feitos heroicos e conquistas) em relação aos textos dos hinos oficiais.

Além disso, pensamos as tradições e os imaginários dos clubes como resultados de processos discursivos de construção a partir de contextos de emergência específicos, cujas marcas ficam registradas no próprio texto da letra de seus respectivos hinos. Seriam, pois, construções que estão na base das "comunidades imaginadas”, como aponta Benedict Anderson. ${ }^{18}$

Por fim, ressaltamos que dificuldades se impõem em estudos dessa natureza, sobretudo com relação à falta de informações e de fontes confiáveis, através das quais possamos não só ter acesso às letras, como também obter maiores informações sobre autoria e contexto em que foram compostas. Mesmo os sites oficiais de clubes, em geral, muitas vezes, dão mais espaço para o marketing, relegando a história das agremiações ao segundo plano. Sendo assim, esperamos que estudos dessa natureza contribuam para resgatar a memória e a história desses clubes, bem como a história do futebol em Portugal.

\section{REFERÊNCIAS}

ANDERSON, Benedict. Imagined Communities. London: New Left Books, 2006
BILAC, Olavo; PASSOS, Guimaraens. Tratado de versificação. 6. ed., São Paulo; Rio de Janeiro: Francisco Alves, 1930

CORNELSEN, Elcio Loureiro. Hinos de futebol - aspectos épicos e dramáticos (entrevista concedida à Rede Minas). Programa Meio de Campo. Belo Horizonte, 2009.

COSTA, António da Silva. Do futebol a uma nova imagem do homem e da sociedade. In: LOVISARO, Martha; NEVES, Lecy Consuelo (org.). Futebol e sociedade: um olhar transdisciplinar. Rio de Janeiro: Ed. UERJ, 2005, p. 13-26.

KAKRIDIS, J.; ANDRÓNIKUS, M. Atletismo na poesia e na arte. In: TSIRAKIS, Stylianos (org.). Os jogos olímpicos na Grécia antiga Trad. de Luiz Alberto Machado Cabral, São Paulo: Odysseus, 2004, p. 159-171.

ROSENFELD, Anatol. O futebol no Brasil. In: ROSENFELD، Anatol. Negro, macumba e futebol. org. Jacó Guinsburg, São Paulo: Perspectiva, 2007, p. 73-106. (Debates; v. 258)

ROSENFELD, Anatol. O teatro épico. São Paulo: Desa, 1965 (Buritis; 5)

\section{SITES CONSULTADOS}

Hinos do Futebol Clube do Porto. Disponível em: http://www. primeiraliga.com/pl/archive/index.php?t-5638.html. Acesso em 20 de novembro de 2011

Hinos do Sport Lisboa e Benfica. Disponível em: http:// universobenfiquista.blogspot.com/2010/03/o-hino-do-benficacensurado-pelo-regime.html. Acesso em 20 de novembro de 2011. 
História da censura do primeiro hino oficial do Sport Club Lisboa e Benfica. Disponível em: http://universobenfiquista.

blogspot.com/2010/03/o-hino-do-benfica-censurado-pelo-

regime.html. Acesso em 20 de novembro de 2011; http://

ontemvi-tenoestadiodaluz.blogspot.com.br/2012/12/avante-

avante-plo-benfica.html. Acesso em: 01 de maio de 2014; http://

raivaescondida.wordpress.com/2010/03/15/o-1\%C2\%BA-hino-do-

sport-lisboa-e-benfica-banido-pelo-estado-novo/. Acesso em: 01

de maio de 2014 